\title{
Juan Trías Vejarano: Del antiguo régimen a la sociedad burguesa. El cambio de visión de Bodino a Hobbes. Madrid: Tecnos, 2019, 265 pp.
}

\section{Mateo Ballester Rodríguez \\ Universidad Complutense de Madrid (España)}

Durante la redacción de la reseña de este libro llegó la triste noticia de la muerte de su autor, Juan Trías Vejarano. Profesor entrañable que deja un afectuoso recuerdo, mantuvo hasta el final su gran inquietud intelectual y su labor investigadora. Muestra de ello es este libro, que el autor concibió como una última aportación, y que tuvo la satisfacción de ver culminada y publicada. No pudo sin embargo acudir a su presentación, que se convirtió en su ausencia en un sentido homenaje.

Esta última obra condensa e integra los diferentes enfoques que han acompañado la vida intelectual de Trías Vejarano, y que quedan de manifiesto en la ecléctica enumeración de sus mayores influencias académicas: Karl Marx, Antonio Gramsci, José Ortega y Gasset, José Antonio Maravall y Pierre Vilar. La obra parte de una preocupación intelectual tradicionalmente marxista, la explicación del tránsito del Antiguo Régimen a la sociedad burguesa, vinculado al desarrollo del modo de producción capitalista. La interpretación del Antiguo Régimen de Trías Vejarano está explícitamente inspirada en el debate entre los autores marxistas Dobb y Sweezy, a inicios de la década de los 50, recogido posteriormente en la obra La transición del feudalismo al capitalismo. Este enfoque sería desarrollado y ampliado años más tarde por el también citado Peter Kriedte, en Feudalismo tardio y capital mercantil. Trías aborda no obstante esta cuestión desde un enfoque diferente, centrándose en los cambios en el pensamiento a partir del estudio de destacados autores de la época. El autor enlaza así con la tradición intelectual de la historia de las ideas y formas políticas en la que se enmarcó preferentemente su actividad investigadora, en el entorno académico del ya citado Maravall y Luis Díez del Corral.

Como los autores marxistas citados, Trías considera el Antiguo Régimen como un periodo de transición, en el que se favorecían desde la esfera política las nuevas dinámicas económicas propias del desarrollo del capitalismo, pero intentando preservar en lo posible las jerarquías sociales, el orden jurisdiccional señorial, el orden corporativo y el régimen de privilegios de la sociedad feudal. Hasta qué grado esto fue así es una compleja y controvertida cuestión, que 
quizás en otras condiciones habría podido ser objeto de mayor desarrollo. Otros enfoques e interpretaciones han enfatizado que el fortalecimiento del poder monárquico se llevó a cabo precisamente en buena medida en paralelo a una acción decidida de limitación del poder de los grupos dominantes tradicionales. Se destaca en este sentido que la monarquía a menudo se apoyó en cuadros procedentes de la burguesía, así como en miembros de la media y baja nobleza y grupos letrados en general, como correa de transmisión del poder monárquico, desplazando y alejando particularmente a la alta nobleza de los centros de poder y toma de decisiones.

Trías retoma y modula en mayor grado esta cuestión en el desarrollo del libro (pp. 128-129), donde señala que durante los siglos del Antiguo Régimen se dieron importantes cambios en la antigua estructura de poder, entre los que destaca el cambio de una monarquía jurisdiccional a una administrativa en el siglo XVII. Su conclusión, en cualquier caso, es que "más que de supresiones, se trata de adiciones y de cambios en la práctica gubernamental; el armazón institucional heredado no se altera". Ejemplo de ello sería "la jurisdicción señorial o feudal que se limitaría, pero no se aboliría hasta las revoluciones liberales o burguesas".

Otra idea asimismo objeto de debate que se asume en la obra sin apenas ser problematizada es la que considera la Monarquía Absoluta como una forma pre-estatal, y no como una primera forma del Estado moderno. Trías se sitúa en la estela de Clavero, Fernández Albadalejo, Hespanha y Pérez Royo, distanciándose así de otro de los grandes académicos marxistas que han abordado esta cuestión, Perry Anderson, cuya obra clásica, El Estado absolutista, no podría suscribir desde el propio título.

La obra de Trías se centra en cualquier caso en los elementos de ruptura que se producen en la época, en particular en el siglo XVII, destacando que los más notables se producen en "el campo de lo mental". El objetivo de la obra es, pues, hacer un estudio de "los hitos en el proceso de constitución de la teoría moderna, con el objetivo de fijar donde se sitúan las rupturas que marcarían el tránsito de un pensamiento premoderno a uno moderno".

La labor que Trías realiza en este sentido es de un enorme valor; el autor rastrea y evidencia las transformaciones en el pensamiento de la época en torno a cuestiones centrales de la organización política y social, a partir del estudio exhaustivo y pormenorizado de la obra de algunos de los autores más influyentes de la época. Los autores elegidos son Bodino, Altusio, Suárez, Grocio y Hobbes, que, además de por su importancia, destacan por la amplitud de sus intereses intelectuales. Esto permite contrastar sus planteamientos en las cuatro cuestiones que son objeto de estudio: el origen y naturaleza de la organización social y política, la concepción de la justicia, los conceptos de soberanía y pacto, y la relación entre religión y política. 
El elenco de autores tiene un claro punto de partida y de llegada: Trías señala a Bodino como el más importante teórico de la monarquía del Antiguo Régimen, en tanto que Hobbes es presentado como "el primer gran teórico de la sociedad burguesa y de la forma política que a ella corresponde". En varios casos nos encontramos con una cierta continuidad entre los cuatro primeros autores, seguida de una quiebra por parte de Hobbes, a quien se atribuye un pensamiento de ruptura radical con lo anterior, y precursor de las concepciones por venir, en cada uno de los temas que se abordan. El estudio es así en buena medida una reivindicación del carácter innovador y avanzado del pensamiento del filósofo inglés.

Aunque Hobbes puede considerarse un adecuado punto de llegada en este estudio de amplio y extenso recorrido, en alguna cuestión no abordada el autor del Leviatán no avanzó las nuevas formas políticas, como es el caso en la concepción moderna de los límites del poder soberano. Viene aquí a la mente la figura posterior de John Locke, quien en determinados aspectos anticipó de forma más consumada las concepciones políticas que caracterizan a la sociedad burguesa que se concibe como estadio final del estudio.

El autor ha realizado un valiosísimo trabajo de sistematización del pensamiento de los autores que aborda. En relación a la primera cuestión, las visiones sobre el origen y naturaleza de la organización social y política, Trías pone el énfasis en el tránsito de una visión jerárquico-corporativa de base aristotélica a una visión individualista, nítidamente distanciada de este referente clásico. Este es uno de los casos en los que más evidente resulta para el autor la continuidad entre los cuatro primeros autores y el rupturismo de Hobbes.

Bodino concede centralidad absoluta a la familia como unidad social básica, de existencia y estructura pre-política, y fundamentada en un poder natural que genera una jerarquización también natural. En Bodino, como en Altusio, Suárez, y Grocio de forma más matizada, el sujeto básico de la organización política, fuente y origen de toda República, no es el individuo sino la familia. Luego ésta se estructura por sucesivas consociaciones, entre las que resultan de particular importancia los estamentos. La idea común a estos autores es la de la sociabilidad natural.

Hobbes rompe con esta mentalidad desde un individualismo que enlaza con el nuevo mecanicismo, basado en leyes uniformes que se aplican a la naturaleza y comportamiento humanos. Su estado de naturaleza, de forma novedosa, es una abstracción y no una realidad histórica de los orígenes de la humanidad. Hobbes niega la sociabilidad de los hombres, desde la afirmación de un radical individualismo y de la inexistencia de jerarquizaciones naturales. Esto fundamenta, junto a su idea de igualdad esencial de los hombres, la idea de lucha de todos contra todos, sobre la que construye su sistema. 
El segundo tema abordado por Trías es el de la concepción de la justicia, donde percibe una evolución más progresiva en los autores abordados. El pensamiento de Bodino se centraría en la identificación con un "orden jerárquico monárquico estamental según el modelo trifuncional establecido en la Edad Media". Altusio seguiría esta estela, desde un firme anclaje en la voluntad de Dios y en la referencia a los textos bíblicos. Suárez supone una continuidad con los anteriores, si bien con una mayor atención a la ley natural, que señala que fue propuesta a los hombres por la luz de la razón y de la revelación divina. En Grocio se da una mayor secularización del derecho natural y una mayor autonomía y diferenciación de éste respecto del derecho divino. Hobbes supone de nuevo un estadio final; Trías lo describe como el primer teórico del derecho natural moderno e individualista, que debe ser recogido por el derecho positivo y garantizado por el Estado, como única instancia que puede garantizarlo. Bien conocida es su afirmación de que los pactos sin la espada son vanos.

La siguiente cuestión, referente a la legitimidad del gobernante y el fundamento de la soberanía, tiene trascendentales implicaciones prácticas en el periodo estudiado, por ejemplo en relación a la licitud de rebelarse contra el soberano en determinados supuestos. La polémica en torno a estas cuestiones esta imbricada a menudo con el arraigo del protestantismo en varios países, y su adopción por gobernantes o segmentos numerosos de la población. Esto explica que se trate del tema al que Trías dedica una mayor atención. La definición del concepto de soberanía es considerada una de las mayores aportaciones de Bodino a la teoría política. Trías se detiene aquí en una concienzuda y valiosa recapitulación de la larga tradición doctrinal que lleva a la afirmación del poder absoluto del soberano, remontándose a la obra de canonistas y civilistas en torno a los conflictos jurisdiccionales entre papado e imperio. La concepción de la soberanía de Bodino sitúa al monarca por encima de los Estados Generales, y fija como limitaciones las derivadas de las leyes de Dios y la naturaleza, si bien una de ellas es que se necesita la aceptación de los Estados Generales en determinadas cuestiones, como en materia tributaria. Queda en cualquier caso excluido el recurso al tiranicidio.

Altusio concede más importancia al pacto de lo que hace Bodino, que era consciente, según Trías, de que este era un elemento central en las formulaciones que enfatizaban la limitación del poder soberano del monarca. Altusio se apoya en las teorías del tiranicidio de autores hugonotes previos. El pacto en Altusio no es entre individuos, sino entre comunidades simbióticas (ciudades, territorios, etc.), que al unirse dan lugar a un ente colectivo (definido por Altusio como imperium, regnum, respublica o populus) que es la fuente última del poder y donde reside la soberanía.

La superioridad en la práctica del gobernante es claramente afirmada, si bien con la decisiva función limitadora de los éforos, encarnados en diferentes 
instituciones en la historia y en los reinos de la época, y que se identifican particularmente con la asamblea de los tres estados. Como representantes de la comunidad, los éforos ejercen la función de limitación, control y deposición en caso de tiranía. El derecho de resistencia sólo podrá ser ejercido autónomamente por los individuos si no hay éforos. Las formulaciones teóricas sobre la soberanía raramente se expresan genuinamente en abstracto y al margen de cuestiones concretas, y los planteamientos de Altusio suponen en este sentido una legitimación de la rebelión holandesa contra Felipe II. Trías vincula el pensamiento de Altusio sobre esta cuestión con las formulaciones de Calvino, y lo pone en contraste con el de Bodino, quien sólo aceptaba el tiranicidio cuando el príncipe no es "absolutamente soberano". Quedaban protegidos por esa delimitación los reyes de España, Francia, Inglaterra y Moscovia entre otros, a cada uno de los cuales había que obedecer "aunque haya cometido todas las maldades, crueldades e impiedades imaginables".

Suárez aborda el tema de la soberanía de forma tangencial en su De legibus, que plantea quién tiene la potestad de dictar leyes, y de forma directa en su Defensio fidei. En el primero, tras negar el derecho divino de los reyes y señalar que el poder reside en la comunidad, señala que una vez que el poder se ha transferido al rey, si estamos ante lo que llama perfecta monarchia, esta cesión es perpetua y "entrega ilimitada de todo el poder que había en la comunidad". Esto es distinto en una república, donde la cesión es temporal, y en las monarquías mixtas, en las que media pacto, costumbre o ley escrita, que limitan el poder absoluto del monarca. Su Defensa fidei es una refutación de las tesis de la soberanía de Jacobo I, en la línea de Roberto Bellarmino, en la que cuestiona la procedencia del poder real directamente de Dios. Volviendo a la idea del origen del poder en la comunidad, Suárez contempla de nuevo la posibilidad de resistencia, si el rey cambiara en tiranía su legítimo poder, y si este poder está limitado "por antiguos y seguros documentos, o por costumbre inmemorial". El principio general, no obstante, es el de que la forma más pura es la de cesión incondicional y plena. El libro insiste en la primacía papal en materia espiritual o eclesiástica, y en la sujeción de los reyes al Pontífice en estos asuntos. Éste puede legítimamente deponer a un príncipe cristiano, particularmente si es cismático o hereje, directamente o eximiendo a sus súbditos de la obediencia.

Grocio recurre asimismo al razonamiento clásico que distingue grados diferentes en el poder del soberano, y posibles limitaciones de éste, en función de cómo ha obtenido la soberanía. Aunque el poder procede en origen del pueblo, Grocio es restrictivo en cuanto a su posibilidad de ejercer resistencia legítima, manteniéndose más cercano a Bodino y Suárez que a Altusio.

Hobbes presenta una vez más un planteamiento radicalmente diferente. La soberanía procede de una cesión puramente individual. No es la familia o 
la comunidad en su conjunto, sino cada uno de los individuos, quienes ceden el derecho a gobernarle a un hombre o asamblea de hombres. Sin soberano no hay comunidad ni institución colectiva alguna, sino el individuo atomizado. La desaparición de referencias a realidades corporativas, familias, colegios, etc. como entes con una identidad diferenciada, sustituidos por una suma de individualidades con un interés común, es para Trías el elemento más evidente de transformación hacia una sociedad burguesa. El pensamiento burgués se concreta en la consideración de individuos guiados por la competencia y el individualismo posesivo, que solventan los conflictos por medio de un contrato entre hombres libres e iguales. Trías destaca el énfasis hobbesiano en que los gobernados pagan con sus impuestos la preservación de seguridad y propiedad por parte del soberano y sus agentes. Hobbes por otro lado, enfatiza Trías, intenta evitar las connotaciones democráticas que se podrían derivar de la idea de una asamblea constituyente del soberano. En el Leviatán encontramos en definitiva, en el particular contexto de las guerras civiles inglesas, una "conjunción de absolutismo político y liberalismo socioeconómico".

La relación entre religión y política es el último tema del estudio, estrechamente ligado a la anterior cuestión de la soberanía. La religiosidad de Bodino es materia de debate, entre otras razones porque en ocasiones presenta las consideraciones en este ámbito en forma de diálogos, en los que a menudo no es evidente su opinión. Trías percibe en el angevino una clara tendencia judaizante, y destaca su actitud crítica hacia concepciones centrales del cristianismo. En contraste con la visión que se afirmará más adelante de un Dios que establece unas leyes inmutables de la naturaleza, Trías resalta el énfasis de Bodino en un Dios actuante, en la tradición del Antiguo Testamento. Sus comentarios defienden un alto grado de tolerancia política en materia de religión, aunque el gobernante pueda identificarse y favorecer un culto concreto. El ejemplo otomano se presenta como contraste positivo a los intentos de erradicar violentamente las divergencias religiosas en Francia y otros entes políticos cristianos. La tolerancia hacia la diversidad religiosa evita además, de acuerdo a Bodino, el ascenso del ateísmo, disolvente del respeto a leyes y gobernantes, y por tanto de la sociedad en su conjunto. Esto lleva a una consideración positiva de la religión en cualquiera de sus manifestaciones, sea esta judía, musulmana, o cualquier variante del cristianismo.

En el calvinista Altusio encontramos de nuevo un Dios en el que prima la voluntad pero, a diferencia de Bodino, con mayor protagonismo de Jesús y el Nuevo testamento. Altusio afirma que "debe establecer y permitir en su reino el administrador del mismo una única religión, y ésta verdadera"; este principio se expresa en forma de intolerancia frente al ateísmo y la impiedad manifiesta, pero se suaviza frente a otras religiones. Debe así permitirse la presencia de judíos, si bien siempre que su culto sea privado, y vivan separados 
del resto e identificados por signos externos. Similar tratamiento se preconiza para los papistas: reclusión de la religiosidad al ámbito privado y limitación del contacto. La relativa tolerancia de estas propuestas tiene motivaciones tanto morales como prácticas, pues Altusio considera la violencia que acarrea la persecución religiosa una fuente de perjuicios para todo el reino.

Francisco Suárez escribe sobre esta cuestión en su texto polémico contra Jacobo I, y en particular contra el juramento de fidelidad que acompañó a la conspiración de la pólvora. Sus argumentos replican en buena medida los del también jesuita Bellarmino de la supremacía papal sobre el monarca, que no se puede afirmar frente a gobernantes gentiles, pero sí ante gobernantes cristianos que han roto con Roma. La condena papal a un rey hereje no legítima su asesinato, algo que se había producido en años previos en dos ocasiones en Francia, pero legitima la invasión externa por un gobernante católico.

En Grocio el principio de tolerancia alcanza un mayor desarrollo, que fue fuente de polémica, y le acarreó ser encarcelado y sufrir exilio. Desde una profunda fe encuadrada en el calvinismo arminiano, Grocio predica la tolerancia, con ciertos límites, incluso para quienes profesan religiones no cristianas. $\mathrm{Su}$ propuesta implica relegar los principios teóricos, que considera la fuente habitual de controversia y que deberían reducirse a un núcleo mínimo fuera de las cuestiones en disputa, para anteponer la atención a las reglas prácticas, comunes por lo general. Grocio aboga por la paciencia y la bondad hacia quien tiene convicciones diferentes. Como excepción, el ateísmo es también en Grocio el destinatario de los juicios más negativos, pues supone la negación de los principios que considera comunes a todas las religiones que tiene en cuenta, y un elemento disolvente de la autoridad y la sociedad. Es por ello la única posición que justificaría una guerra por motivos religiosos. La animadversión tan intensa de todos los autores hacia el ateísmo, y su preocupación por sus efectos en la sociedad, parece ilustrar la relevancia de la cuestión de la increencia en la sociedad de la época, pese a la lógica ausencia de textos en explícita afirmación de esta posición.

Hobbes lleva a un mayor desarrollo el erastianismo que ya se observa en Grocio; la superioridad del poder civil sobre el eclesiástico se encuentra enfáticamente expresada en la imagen de portada del Leviatán, con el soberano sosteniendo espada y báculo. Esto puede interpretarse en un sentido general como expresión de la idea de que no pueden convivir varios poderes en un mismo cuerpo político, y en un sentido más concreto como un rechazo tanto a las aspiraciones papales en el plano universal como a las calvinistas presbiterianas en el seno del ente político-territorial en el que se encuentran. El énfasis en identificar el cristianismo con unas creencias básicas va unido a una amplia idea de libertad religiosa. Según Hobbes existe un núcleo básico de leyes de Dios, que son las de la naturaleza; un 
credo mínimo que es el único necesario para ser un buen cristiano. Este era el caso para el autor entre los cristianos primitivos, que al margen de unas creencias básicas podían seguir a quien quisieran. Los límites de la tolerancia religiosa afectan para este autor de nuevo al ateísmo, así como al catolicismo, si bien en este caso, como ya en época de Jacobo I, no tanto por razones estrictamente religiosas sino por su vinculación a una autoridad alternativa y potencialmente enfrentada al poder civil. Reaparece aquí la central idea hobbesiana de la necesidad de un poder único.

Juan Trías acota clara y certeramente el objetivo de su investigación, que no es el de describir un tránsito de enorme complejidad, sino trazar el contraste entre distintas visiones del orden socio-político, que fueron cambiando en consonancia con las relaciones económicas y la propia sociedad. Aunque el estudio se centra en cinco autores centrales, se complementa y enriquece en todo momento con una visión global y de conjunto del pensamiento de la época. El valioso estudio de Trías, de una enorme erudición, ofrece así una visión detallada y coherente de las continuidades y discontinuidades en el pensamiento político y social del periodo abarcado. La exhaustividad con la que acomete esta labor convierte este libro en una autorizada obra de consulta en torno al pensamiento de estos autores en las centrales cuestiones abordadas.

Muchos de los que le conocimos recordaremos siempre a Juan Trías como un ejemplo de inquietud e integridad intelectual, de amor por la profesión académica, y como un compañero entrañable. 